\title{
A Sensitive Method for Cadmium Determination Using an On-line Polyurethane Foam Preconcentration System and Thermospray Flame Furnace Atomic Absorption Spectrometry
}

\author{
César Ricardo Teixeira TARLeY and Marco Aurélio Zezzi ARrudA ${ }^{\dagger}$ \\ Institute of Chemistry, Department of Analytical Chemistry, State University of Campinas-UNICAMP, \\ P. O. Box 6154, Campinas SP 13084-971, Brazil
}

\begin{abstract}
A new sensitive and low cost method for cadmium determination at $\mu \mathrm{g} 1^{-1}$ levels that combines an on-line preconcentration system with the thermospray flame furnace atomic absorption spectrometry technique (TS-FF-AAS) is described in this work. Cadmium is preconcentrated from an acidic medium ( $\mathrm{pH} 2.0$ ) by forming a complex with ammonium $O, O$-diethyldithiophosphate (DDTP), which is then adsorbed onto polyurethane foam (PUF). The elution step is performed by using $80 \%(\mathrm{v} / \mathrm{v})$ ethanol. The effects of the chemical and flow variables associated with the preconcentration were studied, such as the $\mathrm{pH}$ of formation of the Cd-DDTP complex, the DDTP concentration, the preconcentration and elution flow rate and the mass of adsorbent. The present method was operated in volume-mode ( 2 $\mathrm{ml}$ ) and provided a linear range from 0.4 to $15.0 \mu \mathrm{g} \mathrm{l^{-1 }}$ with a sample throughput of $16 \mathrm{~h}^{-1}$. The increase of power detection related to TS-FF-AAS by coupling the preconcentration system was confirmed by the enhancement of sensitivity ( $c a .5$ times), when compared to the value for TS-FF-AAS alone, thus achieving a low detection limit $(0.12 \mu \mathrm{g}$ $\left.1^{-1}\right)$. The accuracy of the method was confirmed from analyses of spiked water samples and by the use of a reference technique (ETAAS). Certified biological materials were also used for the same purpose.
\end{abstract}

(Received December 17, 2003; Accepted April 5, 2004)

\section{Introduction}

Spectrometry techniques including atomic absorption and emission are together the most commonly used analytical methods for trace metal determination. ${ }^{1}$ Particularly, flame atomic absorption spectrometry (FAAS) is a technique widely used for metal determination due to its selectivity and because of providing low operational costs when compared to the costs of electrothermal atomic absorption spectrometry (ETAAS) and inductively coupled plasma optimal emission spectrometry (ICP OES). Nevertheless, due to the low efficiency of aerosol generation/transport and reduced residence time of the free atoms in the absorption volume, FAAS usually experiences detection limits at $\mathrm{mg} \mathrm{l}^{-1}$ levels, which are incompatible with the levels required nowadays. ${ }^{2}$ Therefore, many efforts have been made in order to improve its detectability. Approaches based on total sample introduction, including boat-in-flame or total nebulizer-burner and atom trapping techniques, which increase the residence time of analytes in the optical path, have been carried out for this purpose. ${ }^{3-5}$ Other procedures based on a preconcentration step prior to detection have also been used to lower the detection limit of FAAS.

Recently, Gáspár and Berndt ${ }^{6}$ have developed a new method for flame atomic absorption spectrometry. In this method, a nickel or superalloy tube placed on the burner head of a FAAS equipment is heated by an air/acetylene flame. The liquid sample is transported into the tube towards a small hot capillary.

† To whom correspondence should be addressed.

E-mail: zezzi@iqm.unicamp.br
As the capillary is heated by the flame simultaneously with the tube furnace, a thermospray is formed because the liquid stream into the capillary is heated and partially vaporized in the capillary tip, thus creating a high speed vapor jet which is directly introduced into the tube. This new design, called thermospray flame furnace atomic absorption spectrometry (TSFF-AAS) is characterized by its efficiency of sample transport and by the increase in residence time of the analytes in the absorption volume, which results in a significant improvement in the detectability. In previous studies, the TS-FF-AAS has been employed for $\mathrm{Cd}, \mathrm{Cu}$ and $\mathrm{Pb}$ determination in biological samples with slurry sample introduction. The results reduced detection limits to $0.5,4.3$ and $3.5 \mu \mathrm{g} \mathrm{g}^{-1}$ for $\mathrm{Cd}, \mathrm{Cu}$ and $\mathrm{Pb}$, respectively. ${ }^{7}$ More recently, studies of TS-FF-AAS were expanded to seventeen elements. Different materials for construction of the capillary (ceramic, $\mathrm{Pt} / \mathrm{Ir}$ and stainless-steel) were also evaluated. ${ }^{8}$ It is important to note that TS-FF-AAS, as FAAS, also allows coupling to on-line preconcentration or separation systems. This is possible because the sample can be transported into the tube furnace by different propellants at high or low pressure, such as those obtained with HPLC and peristaltic pumps, respectively. Thus, the strategy for coupling TS-FF-AAS with an on-line preconcentration system can be employed as an excellent procedure so that lower detection limits, at sub $\mu \mathrm{g}^{-1}$ levels, could be attained.

On-line preconcentration procedures for these systems are usually based on liquid-solid extraction. Its advantages include low sample/reagent consumption, high enrichment factors and high sample throughput. Synthetic adsorbents, such as modified silica $\left(\mathrm{C}_{18}\right),{ }^{9}$ fullerene $\left(\mathrm{C}_{60}\right),{ }^{10}$ Amberlite-XAD-2 resins ${ }^{11}$ and polyurethane foams (PUF) ${ }^{12}$ have successfully been employed 
in solid-phase preconcentration systems. Particularly, PUF is widely used due to its suitable properties, such as high available surface area, high chemical stability, purity and low cost. Moreover, PUF can be used directly (unloaded form) or after loading with chelating agents. ${ }^{12,13}$ In the first case, considering that PUF presents fairly hydrophobic behavior, only neutral complexes, negatively charged complexes or high polarizability molecules can be adsorbed onto its surface. ${ }^{14}$ Chelating agents containing dithiophosphate groups, such as ammonium $\mathrm{O}, \mathrm{O}$ diethyldithiophosphate (DDTP) show stability in an acid medium and react with several transition metals and semimetals, but do not react with alkali and alkali earth metals. Such a chelating agent has been successfully used for cadmium preconcentration systems using modified silica $\left(\mathrm{C}_{18}\right)$ as a hydrophobic adsorbent. ${ }^{15,16}$

Based on the above discussion, the present work describes a simple, inexpensive and sensitive method for cadmium determination at $\mu \mathrm{g}^{-1}$ levels through coupling of TS-FF-AAS with an on-line preconcentration system based on retention of Cd-DDTP complexes on polyurethane foam surface. As an analytical application, cadmium was determined in water samples and in certified biological materials.

\section{Experimental}

\section{Instrumentation}

A Perkin-Elmer Model AAnalyst 300 flame atomic absorption spectrometer equipped with deuterium lamp background correction and operated with an air-acetylene flame was utilized throughout this work. The analytical wavelength for cadmium electrodeless discharge lamp (EDL) as well as other operational conditions such as slit bandwidth and air-acetylene flow rate were defined by the manufacturer. A pure nickel tube (J.\&J. Ethen, 52070 Aachen, Germany) of $10 \mathrm{~cm}$ length and $1 \mathrm{~cm}$ i.d., which contains 6 additional holes of $2.5 \mathrm{~mm}$ on its bottom side, was employed as a flame furnace positioned above the burner head. For keep the nickel tube ca. $5 \mathrm{~mm}$ above the burner head a home-made holder (similar to that used for hydride generation systems) was employed. The capillary (10 cm length, $0.5 \mathrm{~mm}$ i.d. and $2.0 \mathrm{~mm}$ o.d.) used for introducing samples into the nickel tube was made of non-porous $\mathrm{Al}_{2} \mathrm{O}_{3}$ ceramics (Friatec, Mannhein, Germany). The samples were propelled by means of an Ismatec Model IPC peristaltic pump with Tygon tubes and connections made of PTFE. A home-made injector commutator made of acrylic was used to select preconcentration/elution steps. The mini-column used for packing the polyurethane foam was made of polyethylene. In addition, a Perkin-Elmer Model AAnalyst 600 electrothermal atomic absorption spectrometer equipped with Zeeman background correction was used for checking the accuracy. For $\mathrm{pH}$ measurements a Digimed DM 20 (Santo Amaro, Brazil) pH meter was used.

\section{Reagents and materials}

All solutions were prepared in deionized water obtained from a Milli-Q system (Molsheim, Paris, France), and reagents were of analytical grade. Cadmium reference solutions were prepared by diluting a $1.0 \mathrm{mg} \mathrm{l}^{-1}$ cadmium stock solution (Mallinckrodt Baker, Paris, France). The ethanol used as eluent was acquired from Mallinckrodt Baker, and the ammonium salt of DDTP (95\% purity) was obtained from Aldrich (Milwaukee, USA). The commercial open-cell polyether-type polyurethane foam (PUF) was supplied by ATOL (Salvador, Brazil). The mini-column consisted of a polyethylene tube $(1.5 \mathrm{~cm}$ length and $4 \mathrm{~mm}$ i.d.); prior to packing, the polyurethane foam was
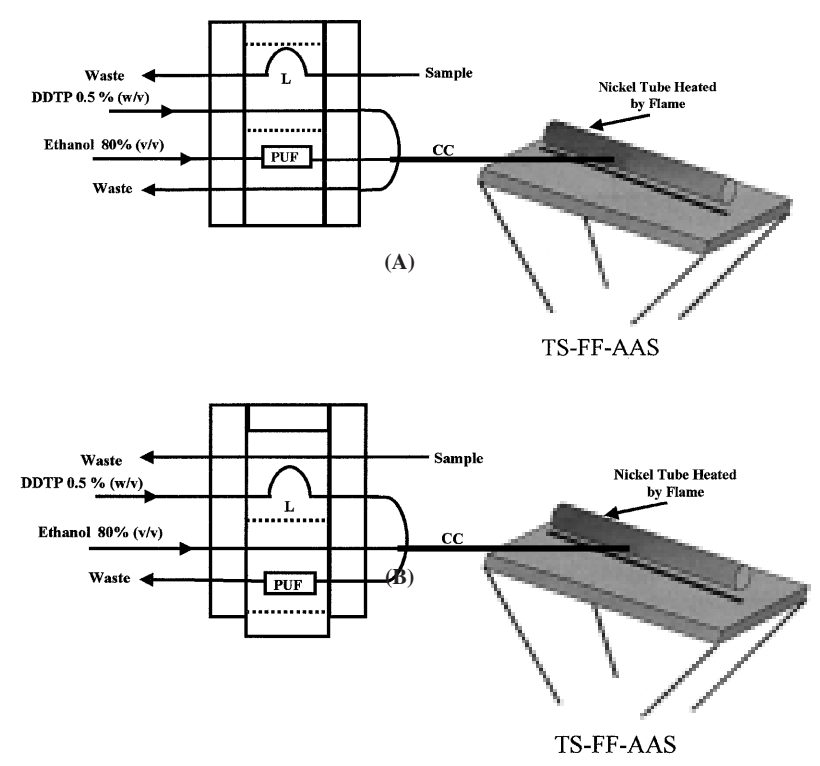

Fig. 1 Diagram of flow injection system coupled to TS-FF-AAS (A) Sampling position which is the same as the elution position; (B) preconcentration position. L, sampling loop of $2.0 \mathrm{ml}$; CC, ceramic capillary and PUF, polyurethane foam.

submitted to a previously described treatment. ${ }^{17}$

Concentrated $\mathrm{HNO}_{3}$ (sub-boiled) (Merck, Darmastadt, Germany) was used in the decomposition procedure of certified biological materials. Solutions of $1.0 \mathrm{~mol} \mathrm{l}^{-1} \mathrm{NaOH}$ and $10 \%$ ( v/v) $\mathrm{HCl}$ were employed for $\mathrm{pH}$ adjustment.

The water samples used for assessing the accuracy of the proposed method, including mineral water and high-salt aqueous samples (physiological and intravenous solutions), were obtained from local markets and drug stores. Lake water samples were obtained from a lake at Unicamp. In addition, the accuracy was checked using certified materials (CRM 186 pig kidney and CRM 281 rye grass), both acquired from the Community Bureau of Reference, Brussels, Belgium.

\section{Sample preparation}

The decomposition process of reference certified materials was carried out using microwave energy in a Provecto Analítica microwave oven (Model DGT100 Plus, Campinas, Brazil). Portions of $350 \mathrm{mg}$ and $250 \mathrm{mg}$ for rye grass and pig kidney, respectively, were weighted into Teflon flasks, followed by addition of $10 \mathrm{ml}$ of concentrated $\mathrm{HNO}_{3}$. The microwaveassisted sample preparation was performed by including two steps: $5 \mathrm{~min}$ at $400 \mathrm{~W}$ and $5 \mathrm{~min}$ at $700 \mathrm{~W}$. The solutions obtained were heated on a hot plate almost to dryness. After cooling, the residues were dissolved in distilled/deionized water and transferred without $\mathrm{pH}$ adjustment to calibrated flasks of 50 $\mathrm{ml}$ and $25 \mathrm{ml}$ for pig kidney and rye grass samples, respectively. Finally, the samples were stored in polyethylene flasks until analysis. Blank solutions were prepared for each sample. The lake water samples were filtered under vacuum through $0.45 \mu \mathrm{m}$ cellulose acetate membranes. Then, they were stored in polyethylene bottles, after $\mathrm{pH}$ adjustment with $10 \%$ (v/v) $\mathrm{HCl}$ solutions, and analyzed by the proposed method. The mineral water and high-salt aqueous samples were subjected only to $\mathrm{pH}$ adjustment with $10 \%(\mathrm{v} / \mathrm{v}) \mathrm{HCl}$ solutions. All water samples were spiked with 1.0 and $2.0 \mu \mathrm{g} \mathrm{l^{-1 }}$ cadmium concentration. 


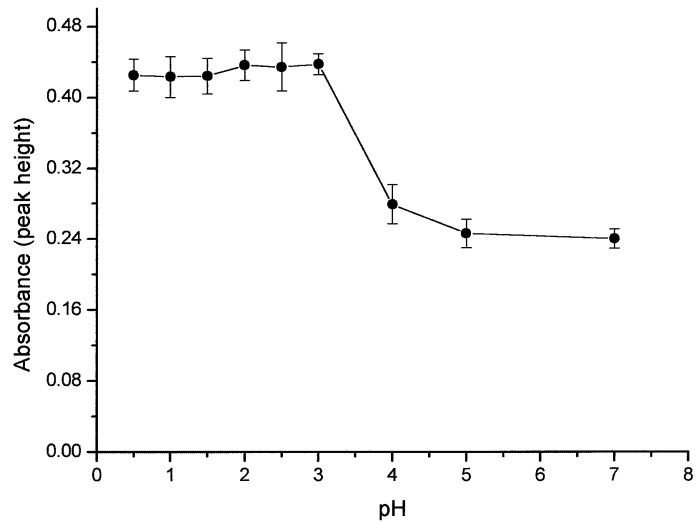

Fig. 2 Effect of $\mathrm{pH}$ on absorbance of $20 \mu \mathrm{g} \mathrm{l}^{-1} \mathrm{Cd}^{2+}$. Operating conditions: $2.0 \mathrm{ml} \mathrm{min}{ }^{-1}$ preconcentration flow rate; $0.5 \%(\mathrm{w} / \mathrm{v})$ DDTP; $20 \mathrm{mg}$ PUF mass and $0.5 \mathrm{ml} \mathrm{min}{ }^{-1}$ elution flow rate of $80 \%$ (v/v) ethanol.

\section{Procedure}

The flow preconcentration system, shown in Fig. 1, was operated in a volume-based mode. Initially, at the sampling position, samples at $\mathrm{pH} 2.0$ fill the loop $(2.0 \mathrm{ml})$ while $0.5 \%$ $(\mathrm{w} / \mathrm{v})$ DDTP solution is discarded to waste. At the same time, an $80 \%$ (v/v) ethanol solution flows through both the minicolumn and heated capillary towards the nickel tube heated by the flame (Fig. 1A). After filling the sampling loop, the injector commutator was switched to the preconcentration position (Fig. 1B), being the sample displaced from the sample loop by $0.5 \%$ (w/v) DDTP at a flow rate of $2.4 \mathrm{ml} \mathrm{min}^{-1}$. The Cd-DDTP complex that formed was adsorbed onto $20 \mathrm{mg}$ of PUF in the mini-column. The time required for the entire volume of $\mathrm{Cd}$ DDTP complex to pass through the mini-column (preconcentration time) was $2.0 \mathrm{~min}$. Afterwards, by again switching the injector commutator for the elution position (the same position as in Fig. 1a) the Cd-DDTP adsorbed onto PUF was released in the opposite direction from the preconcentration step by a stream of $80 \%(\mathrm{v} / \mathrm{v})$ ethanol solution at a flow rate of

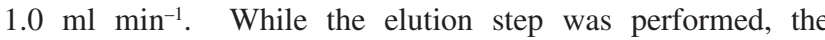
sampling loop was again filled with sample, thus allowing the preconcentration/elution cycles to be carried out. As the elution time was $c a .100 \mathrm{~s}$, the total cycle including sampling, preconcentration and elution was $c a .3 .7 \mathrm{~min}$. Peak height was used as the measurement parameter.

\section{Results and Discussion}

Effect of chemical and flow variables on flow system performance The chemical and flow variables were optimized by using a $20 \mu \mathrm{g} \mathrm{l}^{-1}$ cadmium solution in order to attain the best conditions in terms of detectability.

The $\mathrm{pH}$ value is an important parameter because it significantly affects Cd-DDTP complex formation and consequently the adsorption of this complex on the adsorbent surface. Figure 2 displays the analytical profile of the signals for cadmium when the $\mathrm{pH}$ values are changed from 0.5 to 7.0 . No differences in the absorbance signal were seen within a $\mathrm{pH}$ range from 0.5 to 3.0 , thus indicating the robustness of the method for low values of $\mathrm{pH}$. This is important, because it allows the application of the method to different samples after a sample decomposition process. From these results, a pH of 2.0 was established for further experiments.

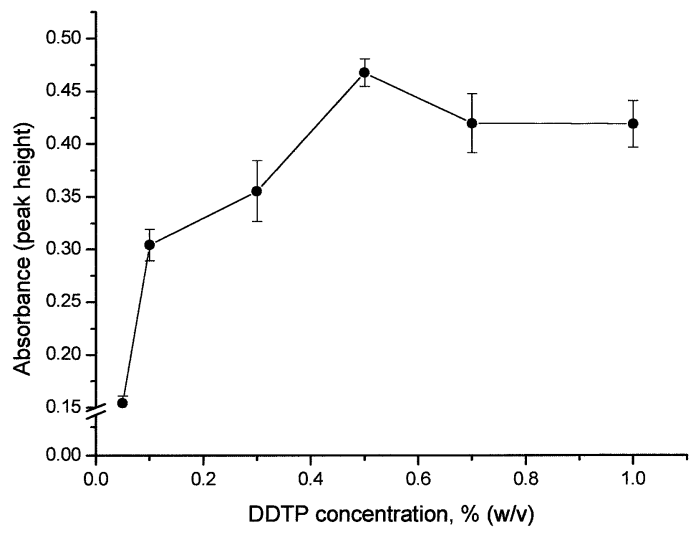

Fig. 3 Effect of chelating agent concentration on absorbance of 20 $\mu \mathrm{g} \mathrm{l}^{-1} \mathrm{Cd}^{2+}$. Operating conditions: sample $\mathrm{pH}=2.0 ; 2.0 \mathrm{ml} \mathrm{min}{ }^{-1}$ preconcentration flow rate; $20 \mathrm{mg}$ PUF mass and $0.5 \mathrm{ml} \mathrm{min}^{-1}$ elution flow rate of $80 \%(\mathrm{v} / \mathrm{v})$ ethanol.

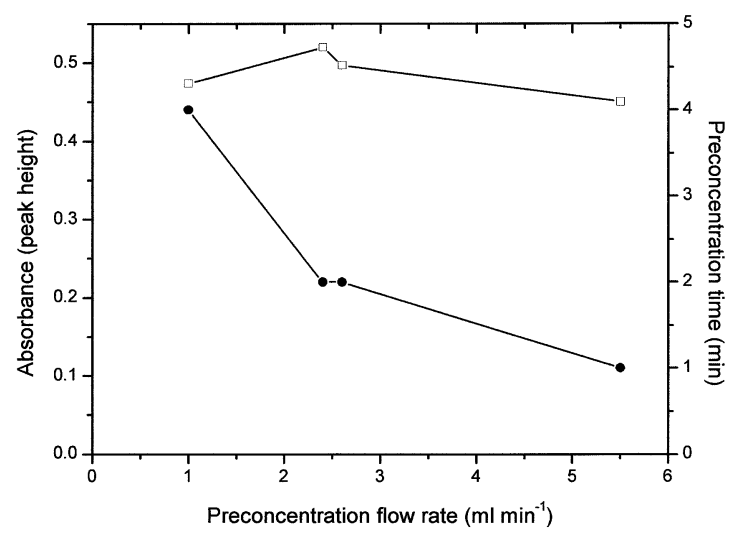

Fig. 4 Effect of preconcentration flow rate on absorbance of $20 \mu \mathrm{g}$ $\mathrm{1}^{-1} \mathrm{Cd}^{2+}$; ( $\square$ ) absorbance values and (๑) preconcentration time. Operating conditions: sample $\mathrm{pH}=2.0 ; 0.5 \%$ (w/v) DDTP; $20 \mathrm{mg}$ PUF mass and $0.5 \mathrm{ml} \mathrm{min}{ }^{-1}$ elution flow rate of $80 \%(\mathrm{v} / \mathrm{v})$ ethanol.

To verify the influence of the DDTP concentration on the absorbance signal, we varied the concentration from 0.05 to $1.0 \%(\mathrm{w} / \mathrm{v})$. As observed in Fig. 3, the effect of the DDTP concentration is more critical than those verified from $\mathrm{pH}$ studies. At lower concentrations, there are not enough DDTP molecules to quantitatively complex $\mathrm{Cd}^{2+}$ ions, decreasing the amount of Cd-DDTP adsorbed on the PUF. On the other hand, at concentrations above $0.5 \%(\mathrm{w} / \mathrm{v})$, the absorbance decreases, probably due to the competition between chelating agent and Cd-DDTP complex for those active sites present on the adsorbent surface. Such behavior has already been verified for a similar liquid-solid preconcentration system based on $\mathrm{Pb}$ DDTP complex adsorption on the PUF surface. ${ }^{18}$ Thus, as the best results were achieved at $0.5 \%(\mathrm{w} / \mathrm{v})$, this concentration was chosen for further experiments.

The behavior of the preconcentration flow rate was studied in the range from 1.0 to $5.5 \mathrm{ml} \mathrm{min}{ }^{-1}$, as shown in Fig. 4. As verified, the absorbance signals at low $\left(1.0 \mathrm{ml} \mathrm{min}^{-1}\right)$ and high $\left(5.5 \mathrm{ml} \mathrm{min} \mathrm{m}^{-1}\right)$ preconcentration flow rates present only slight differences, thus implying that two factors are involved: efficiency of Cd-DDTP formation and its adsorption kinetics on

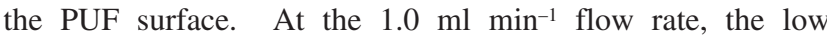
absorbance signal can be attributed to the slow displacement of 


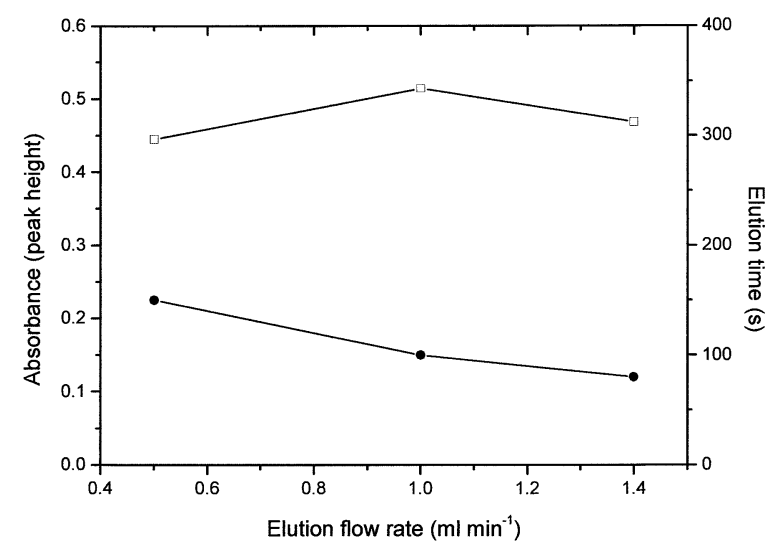

Fig. 5 Effect of elution flow rate on absorbance of $20 \mu \mathrm{g}^{-1} \mathrm{Cd}^{2+}$; $(\square)$ absorbance values and $(\bullet)$ preconcentration time. Operation

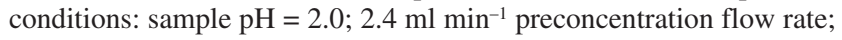
$0.5 \%(\mathrm{w} / \mathrm{v})$ DDTP and $20 \mathrm{mg}$ PUF mass.

sample from the loop by the DDTP solution, which results in a poor complexation efficiency between $\mathrm{Cd}^{2+}$ species and DDTP molecules. On the other hand, at the $5.5 \mathrm{ml} \mathrm{min}^{-1}$ flow rate, a higher amount of Cd-DDTP is formed, thus confirming the fast complex formation. ${ }^{9}$ However, the signal is still lower than that at the intermediate flow rates $\left(2.4\right.$ or $\left.2.6 \mathrm{ml} \mathrm{min}^{-1}\right)$, probably due to slow adsorption kinetics. Similar behavior has been observed in preconcentration systems based on adsorption of $\mathrm{Pb}-\mathrm{DDTP}$ on the PUF surface. ${ }^{18}$ As the formation of the CdDDTP complex is fast, it was not necessary to include a reactor coil prior to the mini-column, which could lead to an increase in the preconcentration time and, as a consequence, to a reduced sample throughput. In addition, it is important to note that the preconcentration flow rate is closely related to the time required for the Cd-DDTP complex to pass through the mini-column. Therefore, 4 and $1 \mathrm{~min}$, respectively, for preconcentration flow rates of 1.0 and $5.5 \mathrm{ml} \mathrm{min}^{-1}$ were necessary for the maximum amount of Cd-DDTP complex to percolate through the minicolumn (Fig. 4). It would seem that a $5.5 \mathrm{ml} \mathrm{min}^{-1}$ flow rate would be the best condition, based on a reduced preconcentration time. However, in such conditions the method became expensive due to the high consumption of chelating agent during the preconcentration cycle. In this way, as a compromise between detectability, sample throughput and reagent consumption, a preconcentration flow rate of $2.4 \mathrm{ml}$ $\mathrm{min}^{-1}$ was selected.

The influence of the elution flow rate of the $80 \%(\mathrm{v} / \mathrm{v})$ ethanol solution for Cd-DDTP complex desorption was studied within the range from 0.5 to $1.4 \mathrm{ml} \mathrm{min}^{-1}$ (Fig. 5). Ethanol was chosen as eluent because it has been successfully employed to desorb metal-DDTP complexes from modified silica $\left(\mathrm{C}_{18}\right)$, PUF and activated carbon. ${ }^{18,19}$ The results obtained from the studies of elution flow rate from 0.5 to $1.4 \mathrm{ml} \mathrm{min}^{-1}$ show that its influence on the absorbance relates to broader peaks and to the desorption kinetics. The best analytical signal was achieved at $1.0 \mathrm{ml}$ $\mathrm{min}^{-1}$. At a low elution flow rate $\left(0.5 \mathrm{ml} \mathrm{min}^{-1}\right)$, the peak height decreases because elution peak was broader, which implies in a longer time to complete the elution step ( $c a .150 \mathrm{~s}$ ). On the other hand, the low signal obtained at a high elution flow rate $\left(1.4 \mathrm{ml} \mathrm{min}^{-1}\right)$ indicates that the elution also depends on the kinetics of desorption. Silva et al. ${ }^{20}$ and Fang et al. ${ }^{21}$ also achieved similar results for Pb-DDTP adsorption on PUF and Cd-DDC adsorption on modified silica $\left(\mathrm{C}_{18}\right)$. Higher elution
Table 1 Evaluation of concomitant ions in cadmium determination by the FI-TS-FF-AAS system

\begin{tabular}{llc}
\hline Concomitant & $\begin{array}{c}\text { Ratio } \mathrm{Cd}^{2+} / \\
\text { concomitant }\end{array}$ & $\begin{array}{c}\text { Recovery of cadmium } \\
\text { analytical signal, \% }\end{array}$ \\
\hline $\mathrm{Cu}^{2+}, \mathrm{Co}^{2+}, \mathrm{Ni}^{2+}$ & $1: 1$ & 100.4 \\
$\mathrm{Mn}^{2+}, \mathrm{Pb}^{2+}, \mathrm{Zn}^{2+}$ & $1: 2$ & \\
$\mathrm{Fe}^{3+}$ & $1: 20$ & 100.5 \\
$\mathrm{Cu}^{2+}, \mathrm{Co}^{2+}, \mathrm{Ni}^{2+}$ & $1: 10$ & \\
$\mathrm{Mn}^{2+}, \mathrm{Pb}^{2+}, \mathrm{Zn}^{2+}$ & $1: 120$ & \\
$\mathrm{Fe}^{3+}$ & $1: 200$ & 106.8 \\
$\mathrm{Cu}^{2+}, \mathrm{Co}^{2+}, \mathrm{Ni}^{2+}$ & $1: 100$ & \\
$\mathrm{Mn}^{2+}, \mathrm{Pb}^{2+}, \mathrm{Zn}^{2+}$ & $1: 200$ & \\
$\mathrm{Fe}^{3+}$ & $1: 2000$ & 70.1 \\
$\mathrm{Cu}^{2+}, \mathrm{Co}^{2+}, \mathrm{Ni}^{2+}$ & $1: 1000$ & \\
$\mathrm{Mn}^{2+}, \mathrm{Pb}^{2+}, \mathrm{Zn}^{2+}$ & $1: 2000$ & \\
$\mathrm{Fe}^{3+}$ & $1: 20.000$ & \\
\hline
\end{tabular}

a. Percentage of recovery compared to a single solution containing only $5.0 \mu \mathrm{g} \mathrm{l}^{-1} \mathrm{Cd}^{2+}$ ions. $n=5$.

flow rates were not tested in order to assure a stable thermospray inside the nickel tube.

The amount of PUF in the mini-column was tested over the range from 20 to $60 \mathrm{mg}$. The results obtained showed that 20 mg were enough to adsorb the Cd-DDTP complex under optimized conditions. Higher PUF masses required excessive elution times $(150 \mathrm{~s})$, which could lead to reduce sample throughput. Thus, $20 \mathrm{mg}$ was employed throughout this work.

\section{Interference study}

Although the DDTP chelating agent does not react with alkali and alkaline earth metals or with elements such as $\mathrm{Al}^{3+}, \mathrm{Cr}^{3+}$, $\mathrm{Cr}^{6+}, \mathrm{Fe}^{2+}$ or $\mathrm{Se}^{6+}$, it may react with $\mathrm{Cu}^{2+}, \mathrm{Co}^{2+}, \mathrm{Fe}^{3+}, \mathrm{Mn}^{2+}, \mathrm{Ni}^{2+}$, $\mathrm{Pb}^{2+}$ and $\mathrm{Zn}^{2+} .9,15,16,19,22$ Hence, the influence of extractability of $\mathrm{Cd}^{2+}$ ions from DDTP in the presence of these metals was investigated in order to verify the selectivity of the method. The assays were carried out by using $5.0 \mu \mathrm{g} \mathrm{l}^{-1} \mathrm{Cd}^{2+}$ solutions containing the following metal ions: $\mathrm{Cu}^{2+}, \mathrm{Co}^{2+}, \mathrm{Fe}^{3+}, \mathrm{Mn}^{2+}$, $\mathrm{Ni}^{2+}, \mathrm{Pb}^{2+}$ and $\mathrm{Zn}^{2+}$, in different proportions. Table 1 shows good recoveries for cadmium, which indicate that the proposed method allows one to distinguish $\mathrm{Cd}^{2+}$ ions with good selectivity even in the presence of several transition metals. Interferences were only observed when excessive concentrations were employed: $\mathrm{Cu}^{2+}\left(5 \mathrm{mg} \mathrm{l}^{-1}\right), \mathrm{Co}^{2+}\left(5 \mathrm{mg} \mathrm{l}^{-1}\right), \mathrm{Ni}^{2+}\left(5 \mathrm{mg} \mathrm{l}^{-1}\right), \mathrm{Mn}^{2+}$ $\left(10 \mathrm{mg} \mathrm{l}^{-1}\right), \mathrm{Pb}^{2+}\left(10 \mathrm{mg} \mathrm{l}^{-1}\right), \mathrm{Zn}^{2+}\left(10 \mathrm{mg} \mathrm{l}^{-1}\right)$ and $\mathrm{Fe}^{3+}(100 \mathrm{mg}$ $\left.1^{-1}\right)$.

\section{Analytical characteristics}

Under optimized conditions, the proposed method was able to determine $\mathrm{Cd}^{2+}$ ions within a linear range from 0.40 to $15.0 \mu \mathrm{g}$ $1^{-1}$. The analytical curve was defined by a typical linear equation, $A=\left(0.00302+0.02934\left[\mathrm{Cd}^{2+}\left(\mu \mathrm{g} \mathrm{l}^{-1}\right)\right]\right.$, with good linearity $(r=0.997)$. The increase of power detection according to TS-FF-AAS achieved by a preconcentration system using only $2.0 \mathrm{ml}$ of sample volume was verified by the enrichment factor achieved (5.2) when compared to that obtained by TS-FFAAS alone. The enrichment factor was calculated as the ratio between the slopes of the FI-TS-FF-AAS analytical curve with TS-FF-AAS. According to this enrichment factor, low detection (LOD) and quantification (LOQ) limits were obtained. Both LOD and LOQ were calculated as the ratios of three and ten times the standard deviations of the blank $(n=20)$ to the slopes of the calibration curves, and were found to be 0.12 and $0.40 \mu \mathrm{g} \mathrm{l}^{-1}$ when FI-TS-FF-AAS system was employed. It is 
Table 2 Results for cadmium determination in spiked water samples obtained by proposed system and to ETAAS as alternative analytical technique

\begin{tabular}{|c|c|c|c|c|}
\hline Sample & $\begin{array}{l}\text { Cadmium } \\
\text { concentration } \\
\text { added/ } / \mu \mathrm{g}^{-1}\end{array}$ & $\begin{array}{c}\text { Cadmium } \\
\text { concentration } \\
\text { found }^{2} / \mu \mathrm{g}^{-1}\end{array}$ & $\begin{array}{c}\text { Recovery, } \\
\%\end{array}$ & $\begin{array}{c}\text { ETAAS/ } \\
\mu \mathrm{g} \mathrm{l}^{-1}\end{array}$ \\
\hline Mineral water & 1.0 & $0.95 \pm 0.03$ & - & $1.03 \pm 0.06$ \\
\hline (brand 1) & 2.0 & $2.04 \pm 0.03$ & - & $2.07 \pm 0.07$ \\
\hline Mineral water & 1.0 & $0.91 \pm 0.06$ & - & $1.07 \pm 0.11$ \\
\hline (brand 2) & 2.0 & $2.01 \pm 0.03$ & - & $2.00 \pm 0.1$ \\
\hline \multirow[t]{2}{*}{ Lake water } & 1.0 & $1.02 \pm 0.03$ & - & $1.10 \pm 0.12$ \\
\hline & 2.0 & $2.10 \pm 0.17$ & - & $2.03 \pm 0.0^{\prime}$ \\
\hline Physiological & 1.0 & $0.92 \pm 0.07$ & 92.0 & - \\
\hline serum & 2.0 & $1.99 \pm 0.08$ & 99.5 & - \\
\hline Intravenous & 1.0 & $0.95 \pm 0.09$ & 95.0 & - \\
\hline solutions & 2.0 & $2.12 \pm 0.13$ & 106 & - \\
\hline
\end{tabular}

a. The results are expressed as mean value \pm standard deviation based on five replicates $(n=5)$ determinations. Confidence interval, 95\%.

Table 3 Results for cadmium determination in certified reference materials

\begin{tabular}{lcc}
\hline \multicolumn{1}{c}{ Sample } & $\begin{array}{c}\text { Certified value/ } \\
\mu \mathrm{g} \mathrm{g}^{-1}\end{array}$ & $\begin{array}{c}\text { Found value/ } \\
\mu \mathrm{g} \mathrm{g}^{-1}\end{array}$ \\
\hline Pig Kidney n.186 (CBR) & $2.71 \pm 0.15$ & $2.51 \pm 0.14$ \\
Rye Grass n.281 (CBR) & $0.120 \pm 0.003$ & $0.114 \pm 0.009$ \\
\hline
\end{tabular}

a. Community Bureau of Reference. Confidence interval, $95 \%(n=3)$.

important to note that when only TS-FF-AAS was used, the LOD and LOQ achieved were, respectively, 0.62 and $2.12 \mu \mathrm{g}$ $1^{-1}$, which are higher than those obtained by the FI-TS-FF-AAS system. From these values it is possible to note an increase in the sensitivity after coupling the flow system to TS-FF-AAS. The precisions $(n=10)$ of the method, assessed as relative standard deviations (RSD), were 4.86 and $3.46 \%$, respectively for cadmium solutions containing 0.5 and $15.0 \mu \mathrm{g} \mathrm{l}^{-1}$. Under the defined conditions of analytical performance, a sample throughput of $16 \mathrm{~h}^{-1}$ was established.

\section{Accuracy and analysis of real samples}

Spiked water samples and certified biological materials were used to evaluate the accuracy of the method. The results for spiked water samples (mineral and lake water) were compared to results from ETAAS, used as a reference technique, in order to verify their accuracy. For aqueous samples with high salt content [physiological samples containing $0.9 \%$ of $\mathrm{NaCl}(\mathrm{w} / \mathrm{v})$ and intravenous solutions, respectively containing $0.860,0.030$ and $0.033 \%(\mathrm{w} / \mathrm{v})$ of $\mathrm{NaCl}, \mathrm{KCl}$ and $\mathrm{CaCl}_{2} 2 \mathrm{H}_{2} \mathrm{O}$, recovery tests based on analyte addition was adopted. Although $\mathrm{Cd}^{2+}$ was not directly determined in these samples, it is interesting to emphasize that the limit of quantification obtained with this method $\left(0.4 \mu \mathrm{g} \mathrm{l}^{-1}\right)$ shows that $\mathrm{Cd}^{2+}$ can successfully be determined in drinking water according to the limit $\left(\leq 5 \mu \mathrm{g} \mathrm{l}^{-1}\right)$ established by EPA. ${ }^{23}$ As listed in Table 2, the results from FITS-FF-AAS and ETAAS are in good agreement at the $95 \%$ confidence level, while the recoveries, which ranged from 92.0 to $106.0 \%$, also confirm the accuracy of the method, even for aqueous samples presenting high salt contents. Table 3 shows that there were no differences between certified values for biological material and the values determined by proposed system FI-TS-FF-AAS.

\section{Conclusion}

The on-line preconcentration system applied to the TS-FF-AAS technique described in this work allows one to attain lower limits of detection than those available with a FI-FAAS preconcentration system. The detectability obtained by this combination is confirmed by reduced sample consumption ( 2.0 $\mathrm{ml}$ ). Moreover, as a complementary advantage, the power of detection related to FAAS was improved $c a .216$ times due to the efficiency of both TS-FF-AAS system and preconcentration system. In addition, the nickel tube and the polyurethane foam are inexpensive and the on-line system is also characterized by low cost, simplicity and a reasonable sample throughput. The use of DDTP as a chelating agent provided good selectivity to the method, which may be applied for cadmium determination in different samples, such as those analyzed in this work. Finally, the present paper combines two strategies to enhance the sensitivity of FAAS (by improving the transport of the sample and by including a preconcentration step), these strategies may also be applied to other relatively volatile metals or different kinds of samples with only minor modifications in the system.

\section{Acknowledgements}

The authors are grateful to the Fundação de Amparo a Pesquisa do Estado de São Paulo (FAPESP, process numbers 01/05614-0 and 99/12124-7) and Conselho Nacional de Desenvolvimento e Tecnológico (CNPq) for fellowships and financial support. The authors are also thank Prof. Carol H. Collins for language assistance.

\section{References}

1. C. V. Vandecasteele and C. B. Block, "Modern Methods for Trace Element Determination", 1993, John Wiley \& Sons, New York, 70.

2. M. G. Pereira and M. A. Z. Arruda, Microchim. Acta, 2003, $141,115$.

3. B. Welz and M. Sperling, "Atomic Absorption Spectrometry", 1999, Wiley-VCH, Weinheim, New York, 20.

4. H. Matusiewicz, Spectrochim. Acta Part B, 1997, 52, 1711.

5. H. Sun, Y. Gao, C. Yuan, Y. Zhang, L. Yang, and D. Zhang, Anal. Sci., 2002, 18, 325.

6. A. Gáspár and H. Berndt, Spectrochim. Acta Part B, 2000 , 55, 587.

7. E. R. Pereira Filho, H. Berndt, and M. A. Z. Arruda, J. Anal. At. Spectrom., 2002, 17, 1308.

8. J. Davies and H. Berndt, Anal. Chim. Acta, 2003, 479, 215.

9. R. Ma, W. Van Mol, and F. Adams, Anal. Chim. Acta, 1994, 285, 33 .

10. M. Soylak, I. Narin, and M. Dogan, Anal. Lett., 1997, 30, 2801.

11. P. K. Tewari and A. K. Singh, Talanta, 2001, 53, 823 .

12. A. N. Anthemidis, G. A. Zachariadis, and J. A. Stratis, Talanta, 2002, 58, 831.

13. V. A. Lemos and S. L. C. Ferreira, Anal. Chim. Acta, 2001, $441,281$.

14. S. G. Dmitrienko and Y. Z. Zolotov, Russ. Chem. Rev., 2002, 71, 159.

15. R. Ma, W. V. Mol, and F. Adams, Anal. Chim. Acta, 1994, 
293, 251.

16. R. Ma and F. Adams, Spectrochim. Acta Part B, 1996, 51, 1917.

17. R. J. Cassella, D. T, Bitencourt, A. G. Branco, S. L. C. Ferreira, D. S. Jesus, M. S. Carvalho, and R. E. Santelli, J. Anal. At. Spectrom., 1999, 14, 1749.

18. S. P. Quináia, J. B. B. da Silva, M. C. E. Rollemberg, and A. J. Curtis, Talanta, 2001, 54, 687.
19. R. Ma and F. Adams, Anal. Chim. Acta, 1995, 317, 215.

20. J. B. B da Silva, S. P. Quináia, and M. C. E. Rollemberg, Fresenius J. Anal. Chem., 2001, 369, 657.

21. Z. Fang, T. Guo, and B. Welz, Talanta, 1991, 38, 613.

22. R. Ma, W. V. Mol, and F. Adams, Anal. Chim. Acta, 1995, 309, 395.

23. Environmental Protection Agency (EPA), "National Primary Drinking Water Standards", 2002. 